\title{
Morphometric and stereological assessment of the effects of zinc oxide nanoparticles on the mouse testicular tissue
}

\author{
Moridian $\mathrm{M}^{1,2}$, Khorsandi $\mathrm{L}^{1}$, Talebi $\mathrm{AR}^{2}$ \\ Cell\&Molecular Research Center, Faculty of Medicine, Ahvaz Jundishapur University of Medical Sciences, \\ Yazd,Iran. layasadat@yahoo.com
}

\begin{abstract}
Objective: To evaluate the effects of zinc oxide nanoparticles (ZNPs) on morphometric and stereological parameters of mouse testis.

Background: ZNPs are increasingly used in sunscreens, biosensors, food additives, pigments, rubber manufacture, and electronic materials. However, the potential toxicity of these nanoparticles is not well understood. Methods: Experimental Groups (ZNP-1, ZNP-2 and ZNP-3) received one of the following treatments daily for 35 days: 5, 50 and $300 \mathrm{mg} / \mathrm{kg}$ ZNPs respectively. Right testis from each animal was fixed in bouin's solution for measurement of total volume of testis, total volume of seminiferous tubules, total volume of interstitial tissue and total number of Leydig cells by stereological methods. Seminiferous tubule diameter and seminiferous epithelium height were assessed by morphometrical method. The left testicles were homogenized for measurement of testosterone concentration.

Results: There was a significant decrease in the weight of testicles in ZNP-3 groups. The stereological and morphometrical parameters were significantly changed in ZNP-2 and ZNP-3 groups. ZNP-2 and ZNP-3 groups also showed a significant decrease in testosterone concentrations $(p<0.05)$.

Conclusion: This study demonstrated that ZNPs can change stereological and morphometrical parameters of the seminiferous tubules and reduce the number of Leydig cells (Tab. 3, Fig. 3, Ref. 36). Text in PDF www.elis.sk. Key words: zinc oxide nanoparticles, seminiferous tubules, Leydig cells, stereology.
\end{abstract}

\section{Introduction}

Spermatogenesis is a complex process of germ cell proliferation and differentiation, which leads to the production and release of spermatozoa from the testis. This elaborate process is dependent

on hormonal and dynamic interactions between somatic cells and germ cells of the testis. The intricate regulation and cellular interactions that occur in the testis provide multiple distinct targets, by which toxicants can disrupt spermatogenesis $(1,2)$. Many recent in vivo and in vitro studies demonstrate that most nanoparticles (NPs) have an adverse or toxic effect on male germ cells $(4,5)$. NPs are materials with at least one dimension $\leq 100$ $\mathrm{nm}$, and this large surface-to volume ratio results in unique characteristics compared to their corresponding bulk materials (6). The administration of NPs to mice resulted in their accumulation in the various tissues including the brain and the testis, indicating that they easily pass through the blood-brain and blood-testis barriers $(7,8)$. Not all NPs will necessarily demonstrate an adverse effect leading to toxicity. For example, some NPs show a beneficial or

${ }^{1}$ Cell\&Molecular Research Center, Faculty of Medicine, Ahvaz Jundishapur University of Medical Sciences, Ahvaz, Iran, and ${ }^{2}$ Department of Anatomical Sciences, International Campus of Shahid Sadoughi University of Medical Sciences, Yazd, Iran

Address for correspondence: L. Khorsandi, Cell \& Molecular Research Center, Faculty of Medicine, Ahvaz Jundishapur University of Medical Sciences, P.O. Box 61335, Ahvaz, Iran.

Phone: +98.611.3720458, Fax: +98.611.3336380 nontoxic effect on spermatogenesis $(9,10)$. It has been reported that nanoselenium diet supplementation produced positive effects on sperm quality in male goats (9).

Thus, NPs must be investigated on a case-by-case basis to determine whether a NP will have a positive or negative effect on spermatogenesis. Metal NPs and their oxides have a considerable number of present and future applications in the medical and industrial fields (11). Among the various metal nanomaterials, zinc oxide nanoparticles (ZNPs) are used in several products such as sunscreens, biosensors, food additives, pigments, rubber manufacture, and electronic materials (12). Delouise reported that ZNPs are nontoxic to cultured human dermal fibroblasts (13). Other reports suggest that these nanoparticles are toxic to neuroblastoma cells (14), vascular endothelial cells (15), liver and kidneys $(16,17)$. There are many qualitative studies of the testis after NPs treatment but the stereological aspects of NPs effects on seminiferous tubule and Leydig cells have received little attention. Thus, present study investigated the ZNPs effects on total volumes of testis, seminiferous tubules and interstitial tissue as well as total Leydig cell numbers.

\section{Materials and methods}

\section{Animals}

In this study, 32 healthy adult male NMRI (Naval Medical Research Institute) mice (6-8 weeks old, 25-30 g) were used. This study was carried out in an ethically proper way by following the guidelines provided. The animals were kept under standard 
laboratory conditions ( $12 \mathrm{~h}$ dark and $12 \mathrm{~h}$ light cycle, relative humidity of $50 \pm 5 \%$ and $22 \pm 3{ }^{\circ} \mathrm{C}$ ) for at least 1 week before the experiment and those conditions were preserved until the end of the experiment. Animal cages were kept clean, and commercial food (pellet) and water were provided ad libitum.

\section{Experimental design}

The mice were randomly divided into the four groups, all of which contained eight animals. The doses of ZNP (Sigma) were selected according to previous studies that demonstrated significant toxicity in rodents (15). The stock solution of ZNP $(2 \mathrm{mg} / \mathrm{ml})$ was prepared in Milli-Q water and dispersed for $10 \mathrm{~min}$ by using a sonicator to prevent aggregation. The stock solution of ZNP was kept at $4{ }^{\circ} \mathrm{C}$ and used within 1 week for the experiments. Prior to each experiment, the stock solution was sonicated on ice for $10 \mathrm{~min}$, then immediately diluted in Milli-Q water. Experimental groups (ZNP-1, ZNP-2 and ZNP-3) received 5, 50 and $300 \mathrm{mg} / \mathrm{kg}$ ZNP for 35 consecutive days, respectively. The duration time of treatment was selected according to the timing of mouse spermatogenesis (18). Control group received saline orally for 35 consecutive days. One day after the last administration, after blood sampling, the mice were sacrificed by cervical dislocation under ether anesthesia. Body and testis weight were recorded at the time of sacrifice. Right testis from each animal was fixed in bouin's solution for measurement of total volumes of testis, seminiferous tubules and interstitial tissue as well as total number of Leydig cells by stereological methods. The left testicles were homogenized for measurement of testosterone concentration.

After dissection, the testis was weighed, and the primary volume (V primary) was measured using the immersion method (19). Briefly, a container with distilled water was placed on the scale and weighed, and then the testicles suspended by a thin thread was immersed in the container so that it was fully covered by water and did not touch the bottom of the container. The new weight in grams, minus the weight of the container and water, divided by the specific gravity of distilled water (1.0) was the volume of the testis in cubic centimeters. The final volume of the testis should be estimated in a stereological study to prevent reference trap.

\section{Testosterone assay}

The blood samples were collected in heparinized centrifuge tubes and centrifuged to obtain serum. Serum testosterone con- centration was measured by radio immunoassay (RIA) method. Testosterone was also extracted from testes as previously described (20). Briefly, testes were homogenized by sonication and centrifuged at $5900 \times g$ for $5 \mathrm{~min}$. The supernatant was combined with an equal volume of ethyl acetate, and the organic phase was dried under a stream of $\mathrm{N} 2$ gas at room temperature and reconstituted in $1 \times$ PBS. The concentration of testosterone by this procedure was estimated by RIA.

\section{Morphometry}

The diameters of the seminiferous tubules and the lumen diameter were measured by fitting a graticule of a calibrated linear scale in the $10 \times$ eyepiece of Leitz microscope at objective lens $40 \times$. Only circular and near circular tubules were assessed. The height of the seminiferous epithelium was calculated by subtracting the lumen diameter from the tubule diameter. For each animal 150 tubules were analyzed (21).

\section{Stereological assessments}

\section{Histology and sampling of sections}

Each testis was embedded randomly in paraffin and sectioned exhaustively into $5 \mu \mathrm{m}$-thick sections. Figure 1 illustrates the sampling of sections. Three sections were collected onto each glass slides. With a random start between the first 20 sections, every 20 th section was sampled (the primary sections). In addition, two sections ahead of every primary section were sampled as the reference section. Because every section was $5 \mu \mathrm{m}$ thick, it follows that there was $100 \mu \mathrm{m}$ between the primary sections and $10 \mu \mathrm{m}$ between a primary section and the corresponding reference section. All primary and reference sections were stained with hematoxylin and eosin $(\mathrm{H} \& \mathrm{E})$.

\section{Microscopes and equipment}

The sections were analyzed at $400 \times$ magnifications by a MP3, $\mathrm{Nr} 3437$ microscope (PZO, Poland) equipped with a projecting arm to project the image onto a monitor, which was attached to the microscope. The applied probes used for the stereological examinations (point-counting grid or counting frame as described below) were superimposed to the monitor so that the microscope projected the image onto the grid. We used two microscopes at the same time for counting the total number of Leydig cells in primary and reference sections.
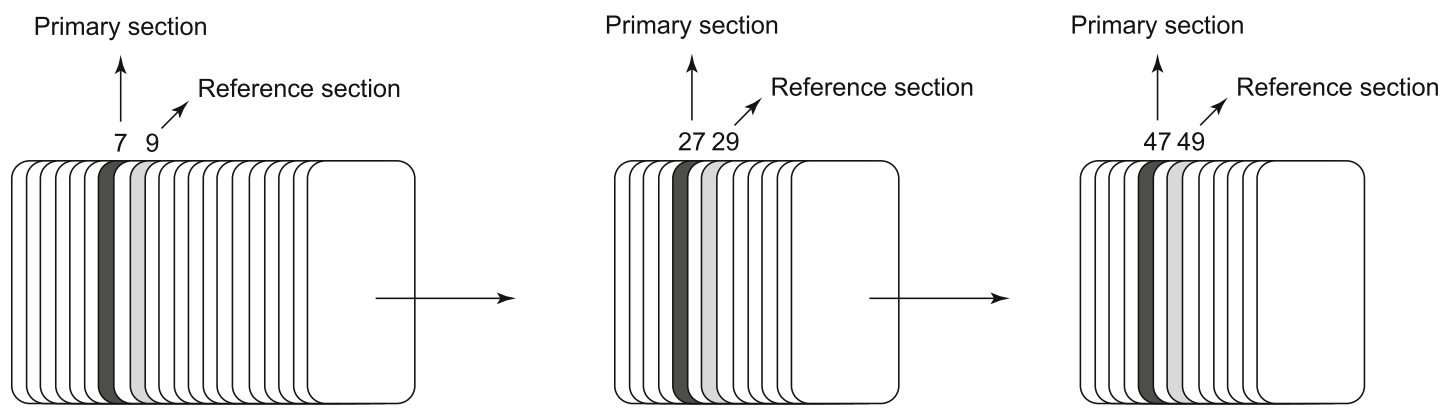

Fig. 1. Sampling method of histological sections is shown. 
3. Total volumes of testis, seminiferous tubules and interstitial tissue

Using step-lengths of $750 \mu \mathrm{m}$ in the $x$-direction $(\Delta x)$ and $550 \mu \mathrm{m}$ in the $y$-direction $(\Delta y)$, all primary sections from each testis were systematically examined. A point-counting grid with 108 points, 1 of them encircled, was applied (Fig. 2A). Moving through all primary sections from the testicles, we counted how many times 1 of the 108 points hit a seminiferous tubules or interstitial tissue. Simultaneously, we counted how many times the encircled point hit testis tissue (seminiferous tubules and interstitial tissue). The values for the total volume of testis, seminiferous tubules and interstitial tissue were then calculated based on the Cavalieri principle $(22,23)$.

1) $\mathrm{V}(\mathrm{Tes})=\mathrm{a} / \mathrm{p}(\mathrm{Tes}) \times \mathrm{N}(\mathrm{p}-\mathrm{p}) \times \mathrm{T} \times \Sigma \mathrm{P}(\mathrm{Tes})=0.095 \mathrm{~mm} 3$ $\times \Sigma \mathrm{P}(\mathrm{Tes})$

Where $\mathrm{V}$ (Tes) is the total volume of testis, a/p (Tes) is the area per point (in this case $\Delta x \times \Delta y$ because only one point in the grid was used to count points that hit testis), $\mathrm{N}(\mathrm{p}-\mathrm{p})$ is the number of sections between the primary sections ( 20 sections in this case), $\mathrm{T}$ is the section thickness $(5 \mu \mathrm{m})$, and $\Sigma \mathrm{P}$ (Tes) is the total number of points that hit testis.

2) $\mathrm{V}(\mathrm{Sem})=\mathrm{a} / \mathrm{p}(\mathrm{Sem}) \times \mathrm{N}(\mathrm{p}-\mathrm{p}) \times \mathrm{T} \times \Sigma \mathrm{P}(\mathrm{Sem})=0.095 \times$ $103 \mathrm{~mm} 3 \times \Sigma \mathrm{P}(\mathrm{Sem})$

Where $\mathrm{V}(\mathrm{Sem})$ is the total volume of seminiferous tubules, $\mathrm{a} / \mathrm{p}(\mathrm{Sem})$ is the area per point and $\Sigma \mathrm{P}(\mathrm{Sem})$ is the total number of points that hit the seminiferous tubules.

3) $\mathrm{V}($ Int $)=\mathrm{a} / \mathrm{p}($ Int $) \times \mathrm{N}(\mathrm{p}-\mathrm{p}) \times \mathrm{T} \times \Sigma \mathrm{P}($ Int $)=0.095 \times 103$ $\mathrm{mm} 3 \times \Sigma \mathrm{P}(\mathrm{Int})$

Where $\mathrm{V}$ (Int) is the total volume of interstitial tissue, a/p (Int) is the area per point and $\Sigma \mathrm{P}$ (Int) is the total number of points that hit the interstitial tissue.

Tissue shrinkage influences all stereological size estimators whether it is distance, surface area, or volume. There is no exact unbiased way to obtain information about tissue deformation during tissue fixation and processing. The area of a piece of testis tissue before and after fixation/processing may be estimated, and the tissue shrinkage can be calculated as (24):

$1-\left(\frac{A-\text { after }}{A-\text { before }}\right)^{1.5}$

\section{Total number of Leydig cells}

In another session, the sampling within the primary sections was performed, but an unbiased counting frame (Fig. 2B) was now attached to the monitor. The rules of the counting frame define objects completely outside the frame or objects that touch the exclusion lines (the full lines in the Figure) as being outside the frame, whereas objects that are completely within the frame or touch only the inclusion lines (the dashed lines in the Figure) are defined as being within the frame. We applied the dissector principle (Sterio, 1984) to count the Leydig cells.

Whenever a Leydig cell was sampled by the counting frame, the corresponding position in the reference section was located with the other microscope, and we determined whether the Leydig cell was also visible in the reference section. The Leydig cell was counted if it appeared in the primary section but not in the

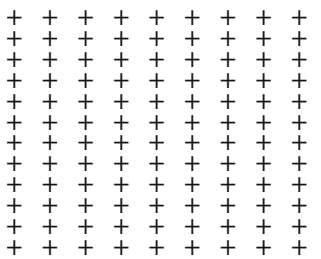

(A)

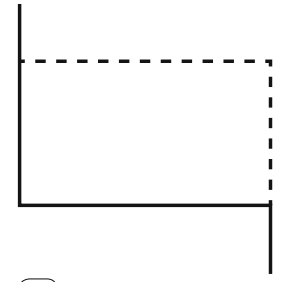

(B)
Fig. 2. Point counting grade (A) and unbiased counting frame (B).

reference section. Because the sampling of sections as well as the within section sampling were performed with known sampling fractions, the total number of Leydig cells can be calculated according to the fractionators principle $(22,23)$ from:

$\mathrm{N}($ Ley $)=\frac{\mathrm{N}(\mathrm{p}-\mathrm{p})}{\mathrm{N}(\mathrm{p}-\mathrm{r})} \times \frac{\Delta x \times \Delta y}{A(\text { frame })} \times \sum \mathrm{Q}^{-}($Ley $)=34.53 \times \sum \mathrm{Q}^{-}($Ley $)$

Where $\mathrm{N}$ (Ley) is the total number of islets in the pancreas, $\mathrm{N}(\mathrm{p}-\mathrm{p})$ is the number of sections between the primary sections, $\mathrm{N}(\mathrm{p}-\mathrm{r})$ is the number of sections between a primary section and the corresponding reference section (two in this case), $\Delta x$ and $\Delta$ $y$ are the step lengths, $\mathrm{A}($ frame $)$ is the area of the counting frame corrected for magnification $\left(412.674 \mu \mathrm{m}^{2}\right)$, and $\Sigma \mathrm{Q}^{-}$(Ley) is the total number of Leydig cells counted in one testis (23).

\section{Results}

Organ weight

No significant changes were observed in Body weight of experimental groups. The weight of testicles in the ZNP-1 and ZNP-2 groups was slightly lower than in the control group ( $p>0.05)$. A significant reduction in testicular weight was observed in the ZNP$3(\mathrm{p}<0.05)$ group (Tab. 1). Relative testes weight was obtained by dividing testes weight by body weight. Relative testes weight in ZNP-3 group was significantly lower than the control group ( $\mathrm{p}$ $<0.05)$. These results are shown in Table 1.

Testosterone assay

To determine whether ZNP affect Leydig cells function, the serum and testis testosterone concentrations were assessed. As illustrated in Figure 3, concentration of the serum and testis testosterone in ZNP-1 group was slightly lower than the control group $(\mathrm{p}<0.05)$. In ZNP-2 and ZNP-3 animals, testosterone levels were significantly decreased compared to the control group. These results are shown in Figure 3.

Morphometry

ZNP-1 group showed no significant alteration in testicular parameters compared to the control group. Diameters of the seminiferous tubules and height of the seminiferous epithelium were significantly decreased in both ZNP-2 and ZNP-3 groups. The results of morphometric studies are shown in Table 2.

Stereology

The present study confirms a $21 \%$ of tissue shrinkage in paraffin embedding. This shrinkage was considered when the final results were reported. In ZNP-1 group, total volumes of testis, seminifer- 

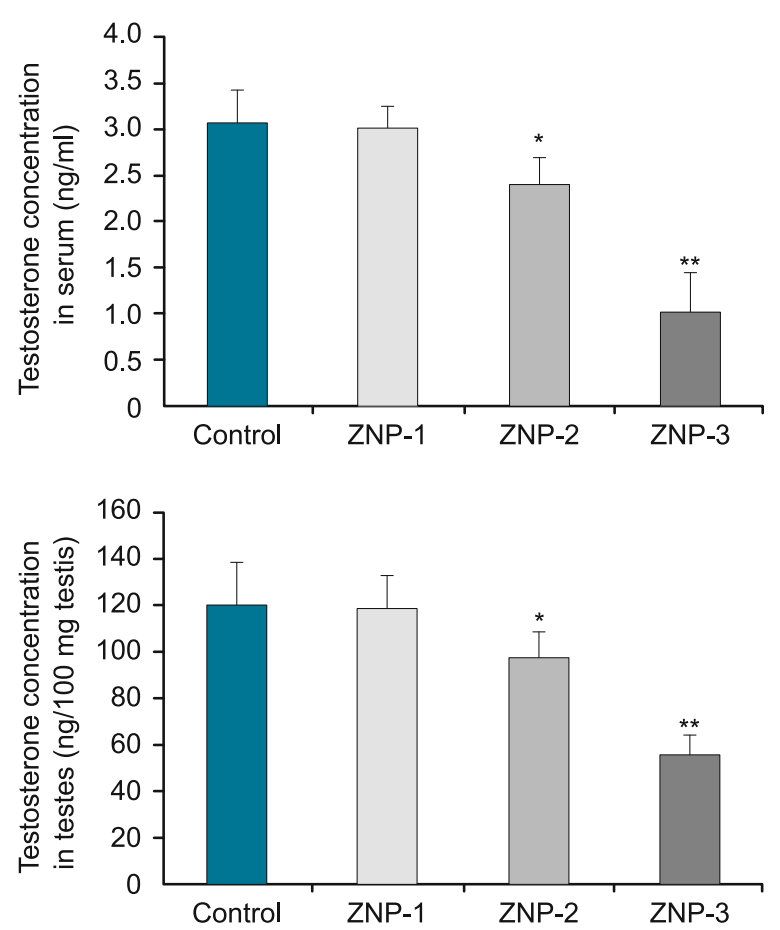

Fig. 3. Testosterone concentrations in control and experimental groups. Values expressed as mean \pm SD for 8 mice. ${ }^{*} p<0.05$, ${ }^{* *} p<0.01$.

ous tubules and interstitial tissue were similar to control group. Total Leydig cell numbers were slightly lower than the control group.

In ZNP-2 group, total testis volume were slightly decreased $(p>0.05)$. Total volume of seminiferous tubules was significantly decreased, while total volume of interstitial tissue was significantly increased. Total Leydig cell numbers were also significantly decreased in comparison to the control group.

In ZNP-3 group, total testis volume and total seminiferous epithelium volume were significantly lower than in the control group ( $p<0.05)$. Total interstitial tissue volume showed a significant increase in comparison to the control group $(\mathrm{p}<0.05)$.

Tab. 2. Morphometrical parameters in control and experimental groups.

\begin{tabular}{lcc}
\hline Group & STD $(\mu \mathrm{m})$ & SEH $(\mu \mathrm{m})$ \\
\hline Control & $218.4 \pm 18$ & $164.3 \pm 9.2$ \\
ZNP-1 & $212.3 \pm 19.2$ & $163.3 \pm 10.9$ \\
ZNP-2 & $187.6 \pm 14.6 *$ & $109.4 \pm 12.1 *$ \\
ZNP-3 & $107.1 \pm 10.9 * *$ & $81.7 \pm 13.5 * *$ \\
\hline
\end{tabular}

Values expressed as mean \pm SD for 8 mice, $* \mathrm{p}<0.05, * * \mathrm{p}<0.01$.

Tab. 3. Sterological parameters in control and experimental groups.

\begin{tabular}{|c|c|c|c|c|}
\hline \multirow{2}{*}{ Group } & \multirow{2}{*}{ Leydig cell number (106) } & \multicolumn{3}{|c|}{ Volume } \\
\hline & & Testis & Seminiferous tubules & Intestitial tissue \\
\hline Control & $2.4 \pm 0.5$ & $126.2 \pm 13.1$ & $102.4 \pm 12.2$ & $13.5 \pm 0.48$ \\
\hline ZNP-1 & $2.2 \pm 0.4$ & $124.8 \pm 9.4$ & $100.3 \pm 7.7$ & $14.1 \pm 0.75$ \\
\hline ZNP-2 & $1.7 \pm 0.8 *$ & $120.7 \pm 12.8 *$ & $87.9 \pm 8.4 *$ & $25.30 \pm 4.7 *$ \\
\hline ZNP3 & $0.8 \pm 0.2 * *$ & $98.1 \pm 10.9 * *$ & $56.9 \pm 9.9 * *$ & $32.53 \pm 3.2 * *$ \\
\hline
\end{tabular}

Values expressed as mean \pm SD for 8 mice, $* \mathrm{p}<0.05$, ** $\mathrm{p}<0.01$
Total Leydig cell numbers were significantly decreased $(\mathrm{p}<0.01)$. These results are reported in the Table 3.

\section{Discussion}

Based on stereological methods (such as fractionators sampling and dissector counting) we found a reduction in the total volume of seminiferous tubules in ZNP treated mice. This reduction was significant in the ZNP-3 group. ZNP treatment also induced a reduction in seminiferous tubule diameter and seminiferous epithelium height. It is well known that increase in seminiferous tubule diameter is indicative of fluid retention resulting from impaired emptying through the efferent ducts, whereas decrease in seminiferous diameter may indicate germ cell loss (25).

Previous studies revealed that NPs have the capacity to penetrate the blood-testis barrier and some of them have toxic action on male germ cells $(26,27)$. Braydich-Stolle et al showed that mammalian spermatogonial stem cells are sensitive to Ag-NPs (28). Thus, the reduction in the total volume of seminiferous tubules may have been a consequence of the germ cells loss induced by ZNPs.

The total volume of interstitial tissue was increased in experimental groups. This may be a consequence of the reduction in the volume of seminiferous tubule or seminiferous tubules diameter. Another possibility is that ZNPs may induce inflammation or edema in interstitial tissue. However, there was not observed unusual leukocyte infiltration in this area. In spite of increase in the total volume of interstitial tissue, the number of Leydig cells was considerably decreased in present study. Leydig cells synthesize and secrete testosterone to blood stream and testicular tissue. The presence of testosterone is essential for normal function and survival of the germ cells in seminiferous tubules (29). When the testicular environment cannot support spermatogenesis, specific mechanisms leading to germ cell death are activated (30). ZNPs also caused a significant decrease in serum and testis tissue testosterone concentrations. Komatsu et al, have reported that titanium oxide and carbon black nanoparticles were taken up by mouse Leydig TM3 cells, and affected their viability, proliferation and gene expression (31). The exact mechanism of ZNPs effects on mouse testicular tissue is not obtained from this study. However, the dose-dependent decrease in seminiferous tubule diameter and total volume of seminiferous tubules indicated ZNPs induced germ cell loss.

Additionally, the reduction in testis weight also indicates that ZNP can induce testicular cell loss including germ cells and somatic cells. As mentioned above, Leydig cell numbers were decreased in ZNPs treated mice. The reduction in the number of leydig cells can lead to decrease in testosterone levels and consequently germ cell death. Sharma et al (2012) reported that ZNP exposure in 
HepG2 cells increased apoptotic cell death (32). Recently, some NPs types have been identified as a novel class of autophagy activators and inducers of autophagic cell death $(33,34)$.

Also, Yu et al (2009) showed that rare element NPs including samarium/ europium and gadolinium/ terbium, induced serious autophagy in human liver cells (35). Yu et al (2013) showed that ZNPs could induce autophagy in normal skin cells (36).

In summary, this study has established that ZNP caused a dose-dependent reduction in testis weight, total volume of testis, total volume of seminiferous tubules, seminiferous tubule diameter, seminiferous epithelium height and total number of Leydig cells. The reduction in the number of Leydig cells led to decrease in testosterone concentrations and this could induce germ cell death. Increase in germ cell loss can lead to the decrease in seminiferous tubule volume and diameter, testis volume and weight. However, to state the mechanism by which ZNP exerts its effects needs more investigations.

\section{References}

1. Franca LR, Ghosh S, Ye SJ, Russell LD. Surface and surface to volume relationships of the Sertoli cells during the cycle of the seminiferous epithelium in the rat. Biol Reprod 1993; 49 (6): 1215-1228.

2. Boekelheide K, Fleming SL, Johnson KJ, Patel SR, Schoenfeld HA. Role of Sertoli cells in injury-associated testicular germ cell apoptosis. Exp Biol Med 2000; 225 (2): 105-115.

3. Cheng CY, Mruk DD. Cell junction dynamics in the testis: Sertoli-germ cell interactions and male contraceptive development. Physiol Rev 2002; 82 (4): 825-874.

4. Braydich-Stolle LK, Lucas B, Schrand A et al. Silver nanoparticles disrupt GDNF/Fyn kinase signaling in spermatogonial stem cells. Toxicol Sci 2010; 116 (2): 577-589.

5. Braydich-Stolle L, Hussain S, Schlager JJ, Hofmann MC. In Vitro cytotoxicity of nanoparticles in mammalian germline stem cells. Toxicol Sci 2005; 88 (2): 412-419.

6. Roduner E. Size matters: why nanomaterials are different. Chem Soc Rev 2006; 35 (7): 583-592.

7. Borm PJ, Kreyling W. Toxicological hazards of inhaled nanoparticles potential implications for drug delivery. J Nanosci Nanotechnol 2004; 4 (5): 521-531.

8. Chen Y, Xue Z, Zheng D et al. Sodium chloride modified silica nanoparticles as a non-viral vector with a high efficiency of DNA transfer into cells. Curr Gene Ther 2003; 3 (3): 273-279.

9. Shi L, Xun W, Yue W et al. Effect of sodium selenite, Se-yeast and nanoelemental selenium on growth performance, Se concentration and antioxidant status in growing male goats. Small Ruminant Res 2011; 96 (1): 49-52.

10. Shi L, Yang R, Yue W et al. Effect of elemental nano-selenium quality, glutathione peroxidase activity, and testis ultrastructure in male Boer goats. Anim Reprod Sci 2010; 118 (2-4): 248-254.

11. Tyner KM, Schiffman SR, Giannelis EP. Nanobiohybrids as delivery vehicles for camptothecin. J Controlled Release 2004; 95 (3): 501-514.

12. Lan Z, Yang WX. Nanoparticles and spermatogenesis: how do nanoparticles affect spermatogenesis and penetrate the blood-testis barrier. Nanomedicine. 2012; 7 (4):579- 596.

13. Delouise LA. Applications of nanotechnology in dermatology. J Invest Dermatol 2012; 132 (3 Pt 2): 964-975.

14. Jeng HA, Swanson J. Toxicity of metal oxide nanoparticles in mammalian cells. J Environ Sci Health A Tox Hazard Subst Environ Eng 2006; 41 (12): 2699-2711.
15. GojovaA, Guo B, Kota RS, Rutledge JC, Kennedy IM, Barakat AI. Induction of inflammation in vascular endothelial cells by metal oxide nanoparticles: Effect of particle composition. Environ Health Perspect 2007; 115 (3): 403-409.

16. Sharma V, Singh P, Pandey AK, Dhawan A. Induction of oxidative stress, DNA damage and apoptosis in mouse liver after sub-acute oral exposure to zinc oxide nanoparticles. Mutat Res 2012; 745 (1-2): 84-91.

17. Wang L, Wang L, Ding W, Zhang F. Acute toxicity of ferric oxide and zinc oxide nanoparticles in rats. J Nanosci Nanotechnol 2010; 10 (12): 86178624.

18. Hess RA, Chen PP. Computer of germ cells in the cycle of the seminiferous epithelium and prediction of changes in the cycle duration in animals commonly used in reproductive biology and toxicology. J Androl 1992; 13: 185-190.

19. Scherle W. A simple method for volumetry of organs in quantitative Stereology. Mikroskopie 1970; 26 (1): 57-60.

20. Habert R, Picon R. Control of testicular steroidogenesis in foetal rat: effect of decapitation on testosterone and plasma luteinizing hormone-like activity. Acta Endocrinol 1982; 99 (3): 466-473.

21. Orazizadeh M, Khorsandi LS, Hashemitabar M. Toxic effects of dexamethasone on mouse testicular germ cells. Andrologia 2010; 42 (4): 247-53.

22. Gundersen HJ, Jensen EB. The efficiency of systematic sampling in stereology and its prediction. J Microsc 1987; 147 (3): 229-263.

23. Bock T, Pakkenberg B, Buschard K. Inctrased islet volume but unchanged islet number in ob/ob mice. Diabetes 2003; 52 (7): 1716-1722.

24. Nyengaard JR. Stereologic methods and their application in kidney research. J Am Soc Nephrol 1999; 10 (5): 1100-1123.

25. Moffit JS, Bryant BH, Hall SJ, Hall SJ. Dose-dependent effects of Sertoli cell toxicants 2, 5-hexanedione, carbendazim, and mono-(2-ethylhexyl) phthalate in adult rat testis. Toxicol Pathol 2007; 35 (5): 719-727.

26. Borm PJ, Kreyling W. Toxicological hazards of inhaled nanoparticles potential implications for drug delivery. J Nanosci Nanotechnol 2004; 4 (5): $521-531$.

27. Chen Y, Xue Z, Zheng D et al. Sodium chloride modified silica nanoparticles as a non-viral vector with a high efficiency of DNA transfer into cells. Curr Gene Ther 2003; 3 (3): 273-279.

28. Braydich-Stolle L, Hussain S, Schlager J, Hofmann M. In vitro cytotoxicity of nanoparticles in mammalian germ-line stem cells. Toxicol Sci 2005; 88 (2) 412-419.

29. Sinha Hikim AP, Swerdloff RS. Hormonal and genetic control of germ cell apoptosis in the testis Rev Reprod 1999; 4 (1): 38-47.

30. Hardy MP, Gao HB, Dong Q, Chai WR. Stress hormone and male reproductive function. Cell Tissue Res 2005; 322 (1): 147-153.

31. Komatsu T, Tabata M, Kubo-Irie M et al. The effects of nanoparticles on mouse testis Leydig cells in vitro. Toxicol In Vitro 2008; 22 (8): 1825-1831.

32. Sharma V, Anderson D, Dhawan A. Zinc oxide nanoparticles induce oxidative DNA damage and ROS-triggered mitochondria mediated apoptosis in human liver cells (HepG2). Apoptosis 2012; 17 (8): 852-870.

33. Chen Y, Yang L, Feng C. Nano neodymium oxide induces massive vacuolization and autophagic cell death in non-small cell lung cancer NCI- H460 cells. Biochem Biophys Res Commun 2005; 337 (1): 52-60.

34. Zabirnyk O, Yezhelyev M, Seleverstov O. Nanoparticles as a novel class of autophagy activators. Autophagy 2007; 3 (3): 278-281.

35. Yu L, Lu Y, Na M, Yu SH, Wen LP. Rare earth oxide nanocrystals induce autophagy in HeLa cells. Small 2009; 5 (24): 2784-2787.

36. Yu KN, Yoon TJ, Minai-Tehrani A et al. Zinc oxide nanoparticle induced autophagic cell death and mitochondrial damage via reactive oxygen species generation. Toxicol in Vitro 2013; 27 (4): 1187-1195.

Received April 5, 2014. Accepted January 20, 2015 